\title{
Polyacrylamide-Grafted Actinidia deliciosa peels powder (PGADP) for the sequestration of crystal violet dye: isotherms, kinetics and thermodynamic studies
}

\author{
Rais Ahmad ${ }^{1}$ (D) $\cdot$ Khalid Ansari $^{1}$ \\ Received: 15 February 2020 / Accepted: 17 June 2020 / Published online: 23 July 2020 \\ (c) The Author(s) 2020
}

\begin{abstract}
Herein, a novel and eco-friendly low-cost adsorbent polyacrylamide-grafted Actinidia deliciosa (Kiwi fruit) peels powder (PGADP) was synthesized and utilized as a potential adsorbent for the sequestration of crystal violet (CV) dye from aqueous solution. The material was characterized by various analytical techniques such as Fourier transform infrared spectroscopy (FTIR), thermogravimetric analysis (TGA), X-ray diffractometer (XRD), scanning electron microscopy (SEM) and transmission electron microscopy (TEM). The adsorption process was carried out in a batch process with different concentrations, adsorbent doses, $\mathrm{pH}$, contact time and temperatures. The maximum adsorption of $\mathrm{CV}$ dye from aqueous solution

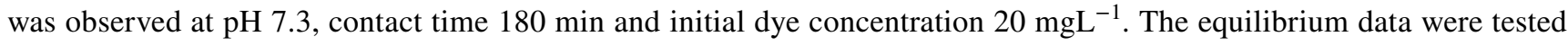
by applying various isotherms models such as Langmuir, Freundlich, Temkin and Dubinin-Radushkevich (D-R), and the results showed that Langmuir was found to be the best fitted model based on the highest correlation coefficient $\left(R^{2}\right)$. Kinetic data showed that pseudo-second order model was best obeyed over wide range of concentrations. In thermodynamic study, positive value of $\Delta \mathrm{H}^{\circ}$ and negative value of $\Delta G^{\circ}$ confirm endothermic and spontaneous nature of adsorption process with increased randomness at solid-solution interface. Desorption of CV dye was performed successfully using $1 \mathrm{M}$ acetic acid with excellent regenerating capacity that lasts up to fourth cycle. Therefore, PGADP can be used effectively and economically for removal of $\mathrm{CV}$ dye from aqueous solution and industrial waste water.
\end{abstract}

Keywords PGADP $\cdot$ Crystal violet dye $\cdot$ FTIR $\cdot$ Langmuir $\cdot$ Regeneration

\section{Introduction}

Numerous studies have demonstrated that azo dyes are a series of synthetic organic compounds that are widely used and applied in different industrial sectors like textile dyeing, paper making, printing and cell biology (Osma et al. 2007; Gupta and Suhas 2009; Konicki et al. 2013). During dye production and textile manufacturing process, a large quantity of wastewater containing dye stuffs with intensive color and toxicity are introduced into the aquatic systems (Ibhadon et al. 2008). The discharge of industrial dye effluent into the water systems and environment has become a serious

Rais Ahmad

rais45@rediffmal.com

1 Environmental Research Laboratory, Department of Applied Chemistry, Faculty of Engineering and Technology, Aligarh Muslim University, Aligarh 202002, India pollution problem and human health risk because of its high visibility and toxicity (Gupta and Suhas 2009; Konicki et al. 2013; Zhang et al. 2014). Due to increasingly drastic restrictions on the organic content of industrial effluents, it is essential to remove dyes from wastewater before it is discharged to the normal water bodies (Ahmad 2009). Many of these dyes are also toxic specifically, the crystal violet (CV) is an organic cationic dye and widely used as textile colorant and biological stain. Several studies indicated that accumulation of CV has been suspected to cause harmful effects such as cancer on human beings (Zhang et al. 2014). Therefore, considerable efforts have been devoted for the treatment of dye effluents using different techniques such as coagulation, flocculation, reverse-osmosis, photo-degradation processes and ion-exchange. Among the various techniques, adsorption process is the most preferred method to remove the dyes from aqueous solution due to its simplicity, efficiency, convenience, ease of operation and inexpensive nature (Martins et al. 2017). 
Activated carbon as an adsorbent has been widely used for the removal of dyes, heavy metals and other organic pollutants from aqueous solution, but its high cost limits its commercial application. In recent years, extensive research has been undertaken to develop alternative and low-cost adsorbents (Ahmad 2009). Adsorbents utilized for dye removal should be characterized by an excellent adsorption capacity derived fundamentally from the combination of pore structure and surface chemistry (Pang et al. 2019). Recent literature survey revealed that various adsorbents have been employed in the treatment of dye-polluted waters includes clay minerals (Kausar et al. 2018), zeolites (Sivalingam and Sen 2019), polymer composite (Jayasantha Kumari et al. 2017), fly ash (Gao et al. 2015) and reduced the cost of adsorption process various biomasses have been suggested as dye adsorbents: rice husks (Franco et al. 2015), grape wastes (Vanni et al. 2017), ouricuri fibers (Meili et al. 2017) and para chestnut husk (Georgin et al. 2018).

Recently, intense research is going on to search for new conventional and low-cost green adsorbent for waste water treatment. Moreover, to further increase mechanical strength and sorption capacity of the conventional adsorbent, the lignocellulosic part was modified by various organic and inorganic compounds, acid and bases and also blended with several synthetic polymers reported elsewhere (Wang et al. 2015), biopolymer (Zhang et al. 2013), metal oxide nanoparticles (Gopalakannan and Viswanathan 2015), nano-clay materials (Hassani et al. 2015) and poly (methyl metha acrylate)-grafted alginate @ Cys-bentonite copolymer hybrid nanocomposite (Hasan and Ahmad 2019). Moreover, phosphate-treated sawdust (lignocellulosic material) shows a remarkable increase in sorption capacity of $\mathrm{Cr}(\mathrm{VI})$ as compared to untreated sawdust (Ajmal et al. 1996). Therefore, to further enhance the capacity of the adsorbent we introduced a suitable procedure for surface modification which involved the grafting of polyacrylamide onto Actinidia deliciosa peels powder using $N, N$ '-methylenebisacrylamide as a cross-linking agent and subsequent functionalization of the polymer network with desired reagent for treating dyes wastewater (Unnithan and Anirudhan 2001). After modification, it was found that the adsorption capacity and stability of the adsorbent materials have increased, which is an important aspect of commercial development of biosorbent materials. In this quest, author has attempted to explore a novel low-cost and abundantly available material Actinidia deliciosa peels powder (ADP) to remove hazardous crystal violet dye (CV) from aqueous solution and waste water.

Herein, we report the preparation of a novel and ecofriendly adsorbent, polyacrylamide-grafted Actinidia deliciosa peels powder (PGADP) and its application for the sequestration of crystal violet (CV) dye from aqueous solution. The experiments were carried out to see the effects of various parameters such as $\mathrm{pH}$, contact time, initial dye concentration and temperature on the adsorption of dye onto (PGADP). The obtained experimental adsorption data were applied to validate the Langmuir, Freundlich, Temkin and Dubinin-Radushkevich (D-R) isotherm models. The equilibrium data were further tested by using pseudo-first, pseudosecond order, intra-particle diffusion and elovich kinetic models. In order to make the process more economical and feasible, the exhausted material was further desorbed and regenerated. To see the morphology of the prepared adsorbent, PGADP was characterized by FTIR, XRD, SEM, EDX, TEM and TGA techniques.

The main novelty of present material PGADP is its high monolayer adsorption capacity of $\left(75.19 \mathrm{mgg}^{-1}\right)$ as compared to other adsorbents in the literature (Table 5). The PGADP also exhibits very good regenerative capability, and it can be used up to fourth cycle successfully without much loss in efficiency for the removal of CV dye. Therefore, PGADP can be used very effectively and economically for the removal of $\mathrm{CV}$ dye from the developing countries.

\section{Experimental section}

\section{Materials and reagents}

Actinidia deliciosa peels (Kiwi fruit) ADP were procured from local market (Aligarh), India. All analytical grade reagents were purchased from commercial sources. N, N'methylenebisacrylamide was purchased from Sigma-Aldrich (USA). Ethylene diamine was provided by Fisher Scientific. Peroxydisulfate and toluene were supplied by Merck, India. Crystal violet dye $\left(\mathrm{C}_{25} \mathrm{~N}_{3} \mathrm{H}_{30} \mathrm{Cl}\right)$ was purchased by $\mathrm{CDH}$, New Delhi. Hydrochloric acid $(\mathrm{HCl})$ and sodium hydroxide $(\mathrm{NaOH})$ used were of analytical grade.

\section{Preparation of adsorbent}

Actinidia deliciosa peels (ADP) were collected from the local market of Aligarh. The peels were washed several times with tap water then double distilled water to remove the adhering dirt and dried in an oven at $80{ }^{\circ} \mathrm{C}$. The dried materials of ADP were crushed to make fine powder. The material was grafted with polyacrylamide using the method reported elsewhere (Unnithan et al. 2004). Firstly, $20 \mathrm{~g}$ of ADP powder was soaked with $300 \mathrm{~mL}$ of solution containing $5 \mathrm{~g}$ of $\mathrm{N}, \mathrm{N}^{\prime}$-methylenebisacrylamide and $2 \mathrm{~g}$ potassium peroxydisulfate for $15 \mathrm{~min}$ before graft copolymerization was started. Then, $7.5 \mathrm{~g}$ of acrylamide was added to the mixture gradually and stirred vigorously at $70{ }^{\circ} \mathrm{C}$ for $3 \mathrm{~h}$. The polyacrylamide-grafted ADP (PGADP) was then washed with double distilled water and dried at $80{ }^{\circ} \mathrm{C}$. To convert material into an anion exchanger, PGADP was refluxed with $25 \mathrm{~mL}$ of ethylenediamine for $8 \mathrm{~h}$. The product was then 
washed with toluene and dried. It was further shaken with $0.1 \mathrm{M} \mathrm{HCl}$ for $4 \mathrm{~h}$ and washed well to remove excess chloride ions and finally dried at $80{ }^{\circ} \mathrm{C}$. The yield percentage of functionalized PGADP (PGADP- $\mathrm{NH}^{3+} \mathrm{Cl}^{-}$) material was found to be $(76.81 \%)$, and the material was stored in an air tight container for further studies.

\section{Characterization}

The elemental analysis and surface morphology of the raw ADP and PGADP before and after adsorption were examined by scanning electron microscope (SEM) equipped with energy-dispersive $\mathrm{x}$-ray spectrometer (EDX) (model JSM 6510LV, JEOL, Japan) after gold coating. The particle size of (PGADP) was examined by high-resolution transmission electron microscope (TEM, JEM 2100, JEOL, Japan). FTIR measurements were recorded in the range of $400-4000 \mathrm{~cm}^{-1}$ with (PerkinElmer 1600 infrared spectrometer) from samples in $\mathrm{KBr}$ pellets. XRD pattern was carried out using (Rigaku, Smart Lab) X-ray diffractometer with $\mathrm{Cu} \alpha$ radiation $\left(\lambda=1.542 \mathrm{~A}^{\circ}\right)$. The absorbance of the $\mathrm{CV}$ dye sample was measured by (T70 UV/VIS Spectrometer, PG Instruments Ltd, U.K.) UV-Vis spectrophotometer at $\lambda_{\max }$ of $588 \mathrm{~nm}$.

\section{Adsorption studies}

The stock solution of $1000 \mathrm{mgL}^{-1}$ of crystal violet dye (CV) was prepared by dissolving requisite amount in double distilled water. The batch adsorption studies were conducted using $0.025 \mathrm{~g}$ of adsorbent, $20 \mathrm{~mL}$ of initial CV (20-100 $\left.\mathrm{mgL}^{-1}\right)$, contact time (5-360 min), adsorbent dose (0.01-0.05 g), $\mathrm{pH}(2-11)$ and temperature at 30 to $50{ }^{\circ} \mathrm{C}$ by shaking in a series of conical flask. Supernatant was separated by filtration using Whatman paper No.1 and determined for remaining dye content. The concentration of dye samples was determined using UV-Vis spectrophotometerfor crystal violet at $\left(\lambda_{\max } 588 \mathrm{~nm}\right)$.

The percent removal of $\mathrm{CV}$ dye from aqueous solution at equilibrium was calculated by the using Eq. (1)

\%removal $=\frac{\left(C_{\mathrm{i}}-C_{\mathrm{e}}\right)}{C_{\mathrm{i}}} \times 100$

where $C_{\mathrm{i}}$ is the initial concentration of dye and $C_{\mathrm{e}}$ is the final concentration of dye.

The amount of adsorbate per unit mass of the adsorbent was evaluated by using Eq. (2).

$q_{\mathrm{e}}=\frac{\left(C_{\mathrm{i}}-C_{\mathrm{e}}\right) V}{W}$

where $q_{\mathrm{e}}\left(\mathrm{mgg}^{-1}\right)$ was the adsorption capacity of the adsorbent, $C_{\mathrm{i}}$ and $C_{\mathrm{e}}$ were the initial concentration and concentration at equilibrium $\left(\mathrm{mgL}^{-1}\right), W$ was the mass of the adsorbent $(\mathrm{g})$ and $V$ was the initial volume of the adsorbate solution in liter $(L)$, respectively (Ahmad and Mirza 2017).

\section{Point of zero charge (pHpzc)}

Point of zero charge was examined by solid addition method using $0.1 \mathrm{M} \mathrm{KCl}$ solution (Rao et al. 2016). Take $20 \mathrm{~mL}$ of $0.1 \mathrm{M} \mathrm{KCl}$ solution in a series of conical flask with $0.025 \mathrm{~g}$ adsorbent and $\mathrm{pH}$ value adjust between 1-12 using $0.5 \mathrm{M}$ $\mathrm{HCl}$ and $0.5 \mathrm{M} \mathrm{NaOH}$ and the solution was left for $24 \mathrm{~h}$. After $24 \mathrm{~h}$, the solutions were filtered and final $\mathrm{pH}\left(\mathrm{pH}_{\mathrm{f}}\right)$ of the solution was measured. The difference between $\mathrm{pH}_{\mathrm{i}}$ and $\mathrm{pH}_{\mathrm{f}}$ was obtained by plotting against $\mathrm{pHi}$.

\section{Breakthrough studies}

Breakthrough studies were carried out by column process. $0.05 \mathrm{~g}$ of PGADP adsorbent was taken in a glass wool supported column ( $0.6 \mathrm{~cm}$ i.d.). $250 \mathrm{~mL}$ solution of $20 \mathrm{mgL}^{-1}$ $\mathrm{CV}$ dye was taken in a column and passed with flow rate of 1 $\mathrm{mL} \mathrm{min}{ }^{-1}$. The effluent was collected in $10 \mathrm{~mL}$ fraction and examined by UV/VIS spectrophotometer. The breakthrough capacity was calculated by plot between $C_{\mathrm{e}} / C_{\mathrm{o}}$ versus volume of effluent.

\section{Results and discussions}

\section{Characterization}

SEM micrograph of raw ADP before grafting Fig. 1a, after grafting with polyacrylamide PGADP Fig. $1 \mathrm{~b}$ and after adsorption of $\mathrm{CV}$ dye onto the surface of PGADP is shown in Fig. 1c. The image of the ADP shows rough and patchy surface morphology which seems to be less porous. After grafting, the SEM micrograph of PGADP showed highly cross-linked and porous structure that provide sites for adsorption of crystal violet dye. The SEM image of CV dye loaded PGADP showed highly smooth and cloudy type of surface that confirms the successful binding and adsorption of dye molecule onto the surface of PGADP. The average size of PGADP was found to be $42.1 \mathrm{~nm}$ as shown in TEM image (Fig. 2).

The EDX and elemental analysis of raw ADP and PGADP before and after adsorption of $\mathrm{CV}$ dyes are reported in Table 1. The major elements present in the spectra of ADP, PGADP and after adsorption of CV dye onto the surface of PGADP, respectively, with percent are shown in Fig. 3a-c. The EDX of ADP showed the presence of $\mathrm{C}$, $\mathrm{O}$ while after grafting represents the spectra of PGADP showed the presence of $\mathrm{C}, \mathrm{O}, \mathrm{N}$ and $\mathrm{K}$ these elements confirmed that grafting onto the ADP was successful. The CV dye-treated PGADP 

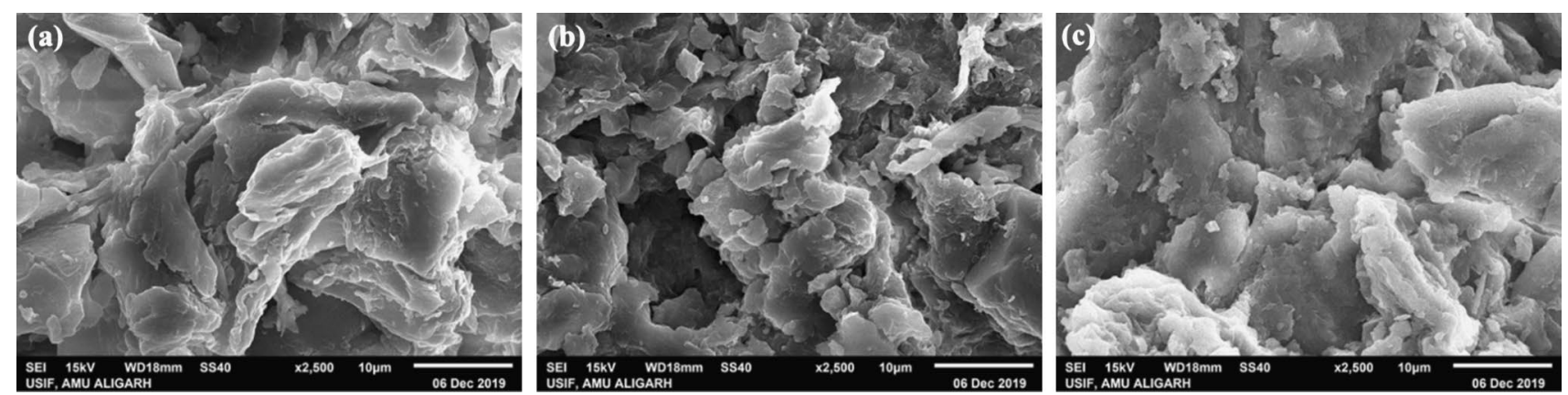

Fig. 1 SEM micrograph a raw ADP b PGADP $\mathbf{c}$ PGADP after CV adsorption (Magnification: $\times 2500$ )

Fig. 2 TEM micrograph of PGADP

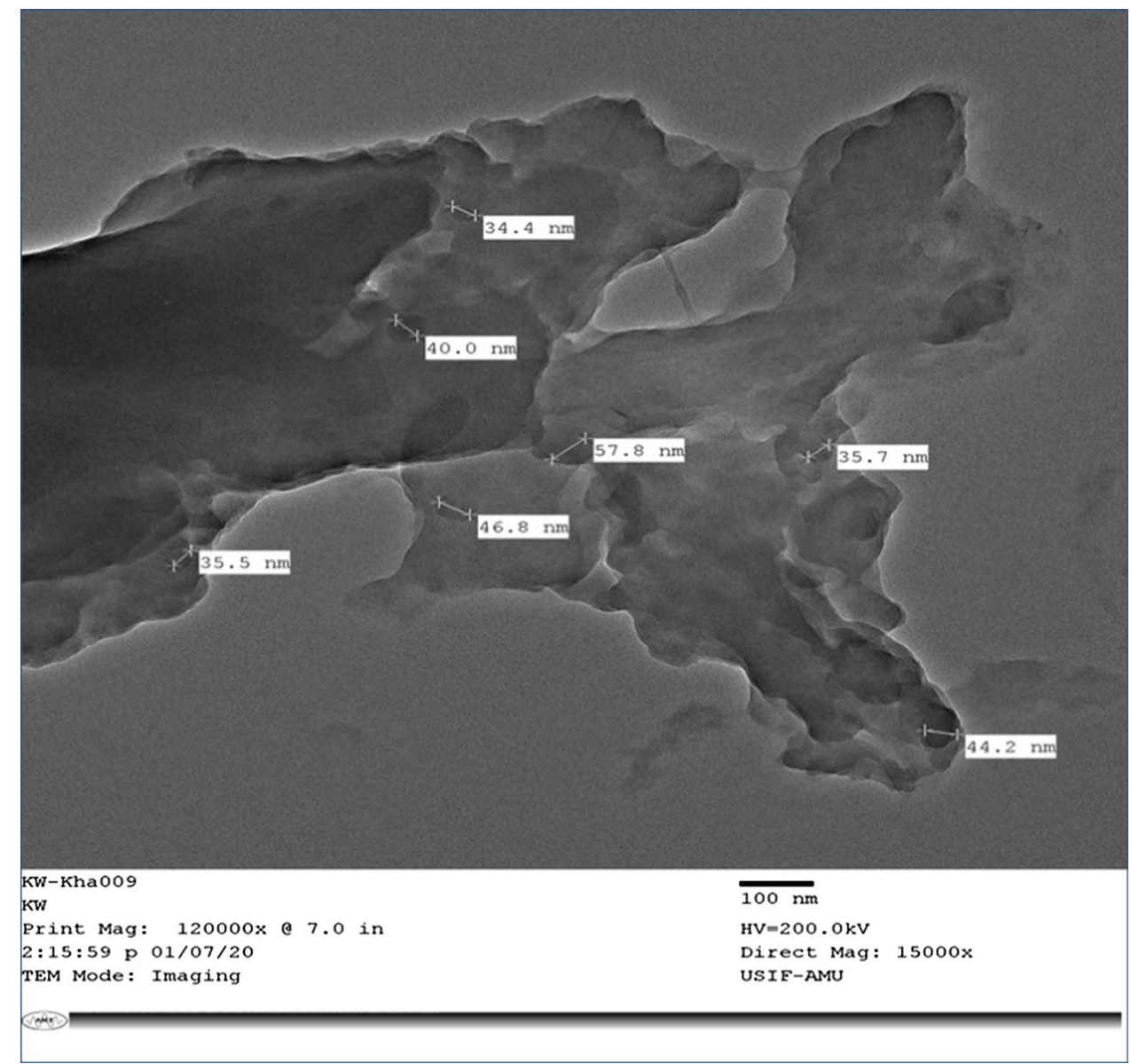

Table 1 EDX analysis of raw ADP, after grafting PGADP and after adsorption of crystal violet dye onto the surface of PGADP

\begin{tabular}{|c|c|c|c|c|c|c|}
\hline \multirow[t]{2}{*}{ Elements } & \multicolumn{2}{|c|}{ ADP before grafting } & \multicolumn{2}{|c|}{ After grafting (PGADP) } & \multicolumn{2}{|c|}{ PGADP after adsorption } \\
\hline & Weight $\%$ & Atomic\% & Weight\% & Atomic\% & Weight\% & Atomic\% \\
\hline $\mathrm{C}$ & 54.91 & 61.86 & 52.75 & 59.57 & 51.09 & 57.81 \\
\hline $\mathrm{O}$ & 45.09 & 38.14 & 43.74 & 37.08 & 42.18 & 35.82 \\
\hline $\mathrm{N}$ & - & - & 3.43 & 3.32 & 6.46 & 6.27 \\
\hline K & - & - & 0.08 & 0.03 & - & - \\
\hline $\mathrm{Cl}$ & - & - & - & - & 0.27 & 0.10 \\
\hline Total & 100.00 & 100.00 & 100.00 & 100.00 & 100.00 & 100.00 \\
\hline
\end{tabular}



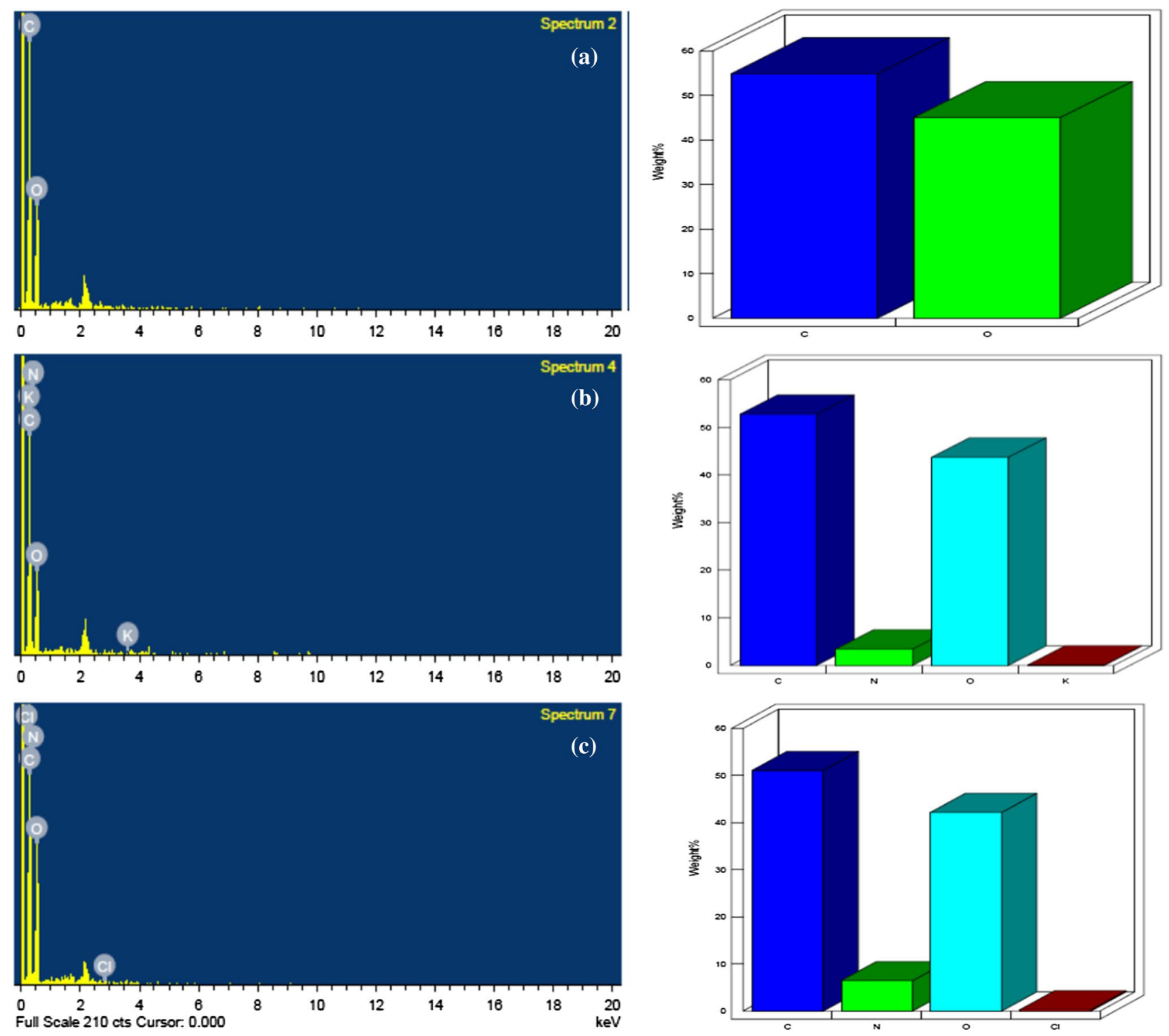

Fig. 3 EDX spectra a raw ADP b PGADP $\mathbf{c}$ PGADP after CV adsorption

showed the presence of $\mathrm{C}, \mathrm{O}, \mathrm{K}, \mathrm{N}$ and $\mathrm{Cl}$ elements. The presence of $\mathrm{N}$ and $\mathrm{Cl}$ in $\mathrm{CV}$ dye adsorbed PGADP spectra further confirms the adsorption of $\mathrm{CV}$ dye onto the surface of PGADP.

For the identification of the crystalline phases present in solid materials, XRD a versatile and nondestructive technique has been carried out. The XRD spectra of PGADP showed sharp peak at $2 \theta$ value at $25.75^{\circ}$ with corresponding $\mathrm{d}$ value of $3.46 \mathrm{~A}^{\circ}$ and showed another peak at $43.22^{\circ}$ with corresponding $d$ value of $2.09 \mathrm{~A}^{\circ}$ as shown in (Fig. 4). The XRD pattern of PGADP revealed semi-crystalline nature of the material with a strong characteristic peak due to grafting with polyacrylamide.
FTIR spectra of raw ADP, PGADP and PGADP after the adsorption of $\mathrm{CV}$ dye on the surface of material are shown in Fig. 5a-c. FTIR spectra of raw ADP Fig. 5a show a broad peak at $3408 \mathrm{~cm}^{-1}$ due to $-\mathrm{OH}$ stretching vibration (Ali Khan Rao and Khatoon 2017). The band at $2924 \mathrm{~cm}^{-1}$ and $2857 \mathrm{~cm}^{-1}$ was aroused due to the presence of $-\mathrm{CH}_{2}$ group asymmetric and symmetric stretching ( $\mathrm{Li}$ et al. 2007). A short and weak peak at $1750 \mathrm{~cm}^{-1}$ was assigned due to $\mathrm{C}=\mathrm{O}$ group (Abdolali et al. 2015). The peak at $1640 \mathrm{~cm}^{-1}$ and $1444 \mathrm{~cm}^{-1}$ attributed due to the carboxylate ions $\left(-\mathrm{COO}^{-}\right)$and $\mathrm{N}-\mathrm{H}$ stretching vibrations of amine group, respectively (Ma et al. 2014; Ali Khan Rao and Khatoon 2017). A strong absorption peak at $1066 \mathrm{~cm}^{-1}$ was aroused due to C-N stretching vibration of 


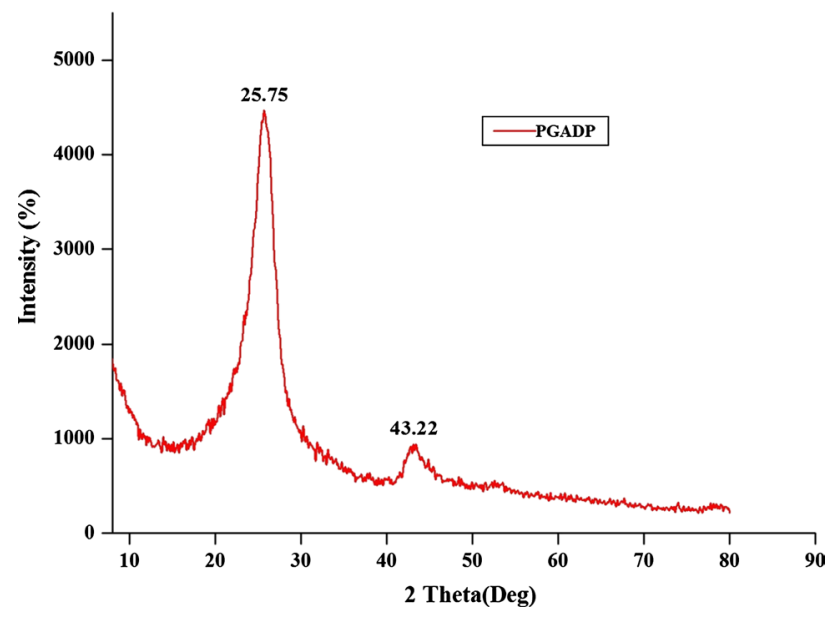

Fig. 4 XRD spectra of PGADP

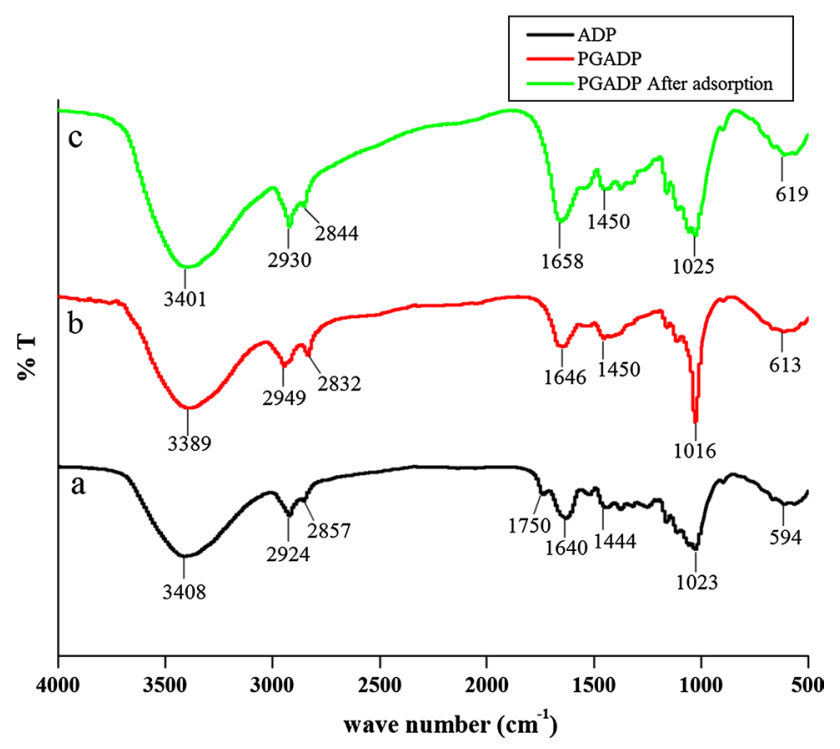

Fig. 5 FTIR spectra a raw ADP b PGADP c PGADP after CV adsorption

aliphatic amines (Hossain et al. 2014). A short and broad band at $594 \mathrm{~cm}^{-1}$ corresponds to metal oxide bond (Wang et al. 2013). FTIR spectra of PGADP in Fig. 5b showed the absorption peak at $1750 \mathrm{~cm}^{-1}$ was disappeared while absorption peak at 3408, 2924, 2857, 1640, 1444, 1023 and $594 \mathrm{~cm}^{-1}$ was shifted to $3389,2949,2832,1646$, 1450,1016 and $613 \mathrm{~cm}^{-1}$, respectively. All these changes noticed that the grafting of polyacrylamide onto raw material (Actinidia deliciosa) peels fetch some change in the functional groups of ADP, specifically in $\mathrm{C}=\mathrm{O}$ groups, whereas the crystal violet-loaded adsorbent showed peaks at 3401, 2930, 284, 1658, 1450, 1025 and 619 and $448 \mathrm{~cm}^{-1}$, respectively (Bizani et al. 2006; Sobana et al. 2006). There are shifting of peaks in PGADP after being treated with $\mathrm{CV}$ dye that showed successful adsorption of dye onto the surface of PGADP.

The TGA thermogram of PGADP in Fig. 6 showed that the degradation occurs in two steps. Due to loss of physically adsorbed water, the initial weight loss occurs at $97.51{ }^{\circ} \mathrm{C}$. The weight loss at $388.01{ }^{\circ} \mathrm{C}$ is accredited due to dehydration process, segmentation of cross-links and decarboxylation of anion. The thermogram clearly signifying greater thermal stability of the prepared adsorbent PGADP by decomposition at higher temperature.

\section{Effect of operational factors on adsorption}

\section{Effect of $\mathrm{pH}$ and $\mathrm{pH}$}

The solution $\mathrm{pH}$ greatly affects the adsorption process by influencing the surface charge of the adsorbent and also the degree of ionization of adsorbate species present in the solution. The test for the effect of $\mathrm{pH}$ (ranging 2-11) on adsorption process was carried out at experimental conditions by taking dye concentration $20 \mathrm{mgL}^{-1}$ and $0.025 \mathrm{~g}$ of adsorbent for $24 \mathrm{~h}$ at room temperature. The adsorption capacity $\left(\mathrm{q}_{\mathrm{e}}\right)$ of $\mathrm{CV}$ dye increases (9.126 to $15.337 \mathrm{mgg}^{-1}$ ) with increase in $\mathrm{pH}$ and reaches maximum at $\mathrm{pH} 7.3\left(15.337 \mathrm{mgg}^{-1}\right)$ as shown in Fig. 7a. After pH 7.3, there is decrease in adsorption capacity. This fact could be explained as-at higher $\mathrm{pH}$, there is electrostatic attraction between the negatively charged sites of the adsorbent and positively charged dye molecules till $\mathrm{pH}$ (7.3). With further increase in $\mathrm{pH}$, the dye molecule starts deprotonating and competes with increased $\mathrm{OH}$ ions at higher $\mathrm{pH}$ which results in further decrease in adsorption capacity. Therefore, for further experimental studies, $\mathrm{pH} 7.3$ was selected as optimum $\mathrm{pH}$ and similar results were also reported by (Sahoo et al. 2005).

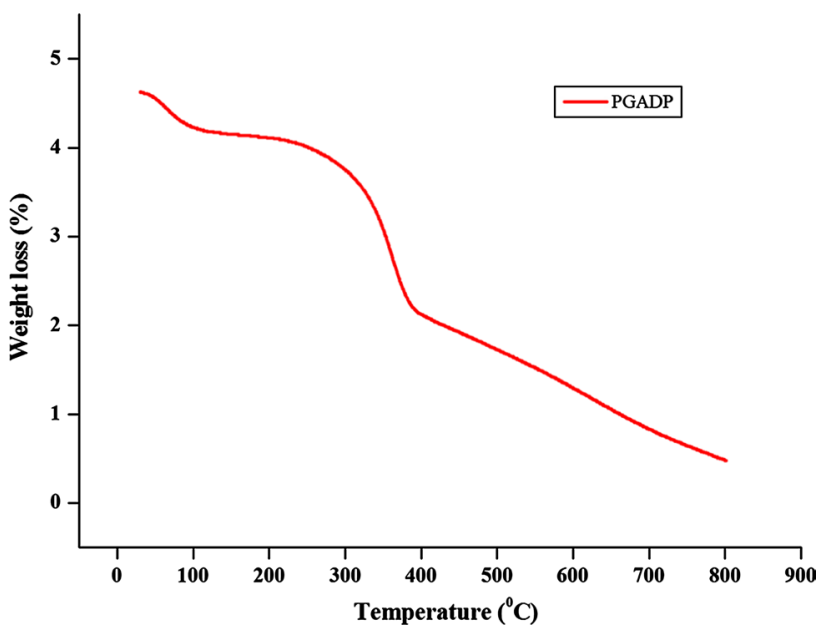

Fig. 6 TGA thermogram of PGADP 

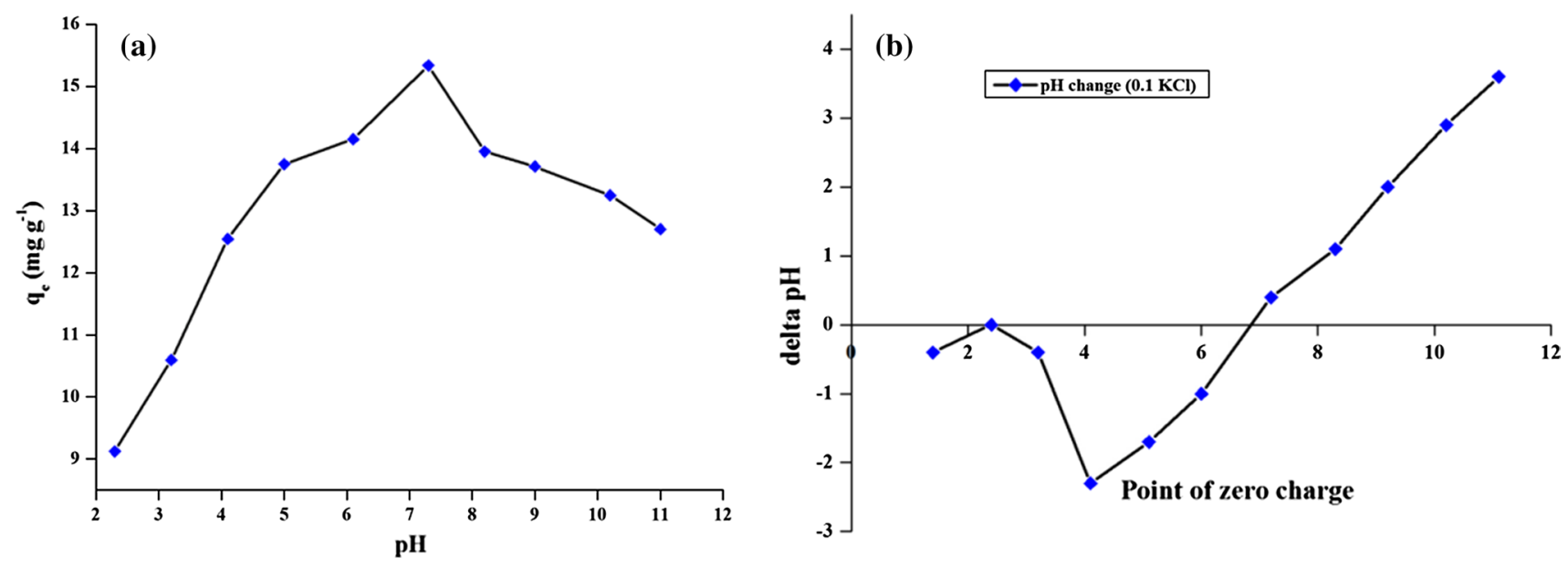

Fig. 7 a Effect of $\mathrm{pH}$ and adsorption of $\mathrm{CV}$ onto PGADP b Point of zero charge (conditions; adsorbent dose $=0.025 \mathrm{~g}$; $\mathrm{CV}^{2}=20 \mathrm{mgL}{ }^{-1}$; temperature $=30^{\circ} \mathrm{C}$ )

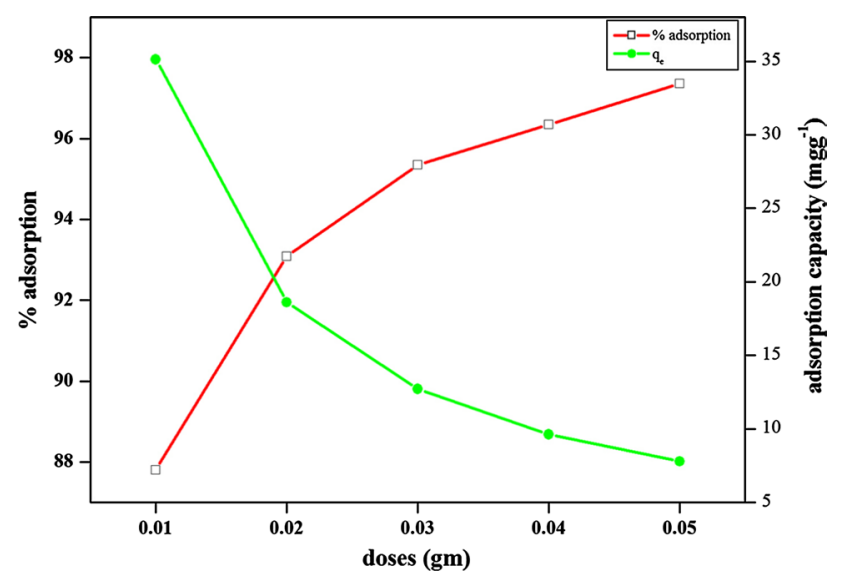

Fig. 8 Effect of doses on the adsorption of $\mathrm{CV}$ onto PGADP (conditions; $\mathrm{CV}=20 \mathrm{mgL}^{-1} ; \mathrm{pH}=7.3$; temperature $=30^{\circ} \mathrm{C}$ )

The point of zero charge of PGADP was found at 2.4. If the $\mathrm{pH}^{>} \mathrm{pH}_{\mathrm{pzc}}$, then the surface of adsorbent is negatively charged. Figure $7 \mathrm{~b}$ showed that the surface of PGADP is negatively charged and the adsorption increased onto the surface by the attraction of positive charge $\mathrm{CV}$ dye and also reported by elsewhere (Martins et al. 2017).

\section{Effect of adsorbent dose}

One of the parameters that strongly affects the sorption capacity is the amount of the adsorbent. With fixed dye concentration $\left(20 \mathrm{mgL}^{-1}\right)$, contact time (24 h), $\mathrm{pH}$ (7.3), it can be easily inferred that the percent removal of dye increases while the adsorption capacity decreases with increasing amount of the adsorbents (0.01-0.05 g). Figure 8. Showed that the percent adsorption increases from 87.81 to $97.36 \%$

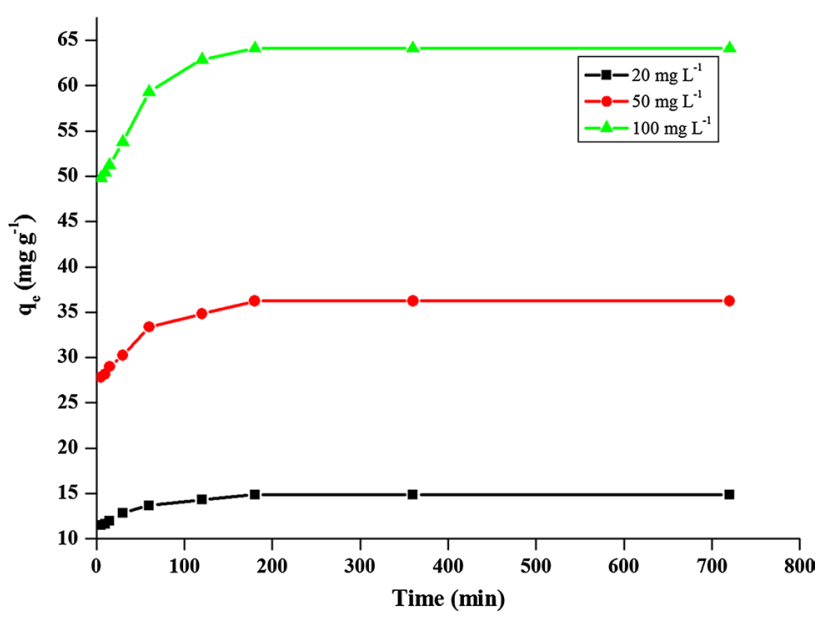

Fig. 9 Effect of contact time on the adsorption of CV onto PGADP (conditions; $\mathrm{pH}=7.3$; adsorbent $=0.025 \mathrm{~g}$; temperature $=30^{\circ} \mathrm{C}$ )

and adsorption capacity decreases from 35.13 to $7.79 \mathrm{mgg}^{-1}$ with increasing adsorbent dose. This is due to greater availability of the exchangeable sites or surface area at higher concentration of the adsorbent (Mirza and Ahmad 2020).

\section{Effect of contact time and kinetic study}

The test for the effect of contact time (ranging 5-720 min) on adsorption process was carried out at experimental conditions taking $0.025 \mathrm{~g}$ dose of adsorbent with varied $\mathrm{CV}$ dye concentration 20,50 and $100 \mathrm{mgL}^{-1}$ at room temperature and $\mathrm{pH}$ (7.3), respectively. As seen from Fig. 9, the adsorption capacity increases with increase in contact time (till $180 \mathrm{~min}$ ) and after the equilibrium time, no significant changes were observed in the adsorption capacity. This 
could be explained as the increase in adsorption capacity in initial stages is due to the high availability of adsorption sites (till $180 \mathrm{~min}$ ) and after that, dye molecules have to compete for available adsorption sites (Song et al. 2008). Therefore, for further experimental studies contact time of 180 min was selected.

To examine the rate, mechanism and rate controlling step of adsorption behavior of adsorbate onto PGADP, various kinetic models were tested namely pseudo-first order pseudo-second order, intra-particle diffusion and elovich kinetic models. Eqs. (3-6) for these models, respectively, are as follows:

$\log \left(q_{\mathrm{e}}-q_{\mathrm{t}}\right)=\log q_{\mathrm{e}}-\frac{k_{1} t}{2.303}$

$\frac{t}{q_{\mathrm{t}}}=\frac{1}{k_{2} q_{\mathrm{e}}^{2}}+\frac{t}{q_{\mathrm{e}}}$

$q_{\mathrm{t}}=K_{i d} t^{1 / 2}+C$

$q_{\mathrm{t}}=A+B \ln t$

where $q_{\mathrm{t}}\left(\mathrm{mgg}^{-1}\right)$ and $q_{\mathrm{e}}\left(\mathrm{mgg}^{-1}\right)$ are the adsorption capacity at contact time $(t)$ and at equilibrium, $k_{1}\left(\mathrm{~min}^{-1}\right)$ and $k_{2}\left(\mathrm{~g} \mathrm{mg}^{-1} \mathrm{~min}^{-1}\right)$ are the constants of pseudo-first order and pseudo-second order equation, respectively. $K_{\mathrm{id}}\left(\mathrm{mg} \mathrm{g}^{-1}\right.$ $\left.\min ^{-1 / 2}\right)$ is the intra-particle diffusion rate constant and $C$ is the intercept. $A\left(\mathrm{mg} \mathrm{g}^{-1} \mathrm{~min}^{-1}\right)$ and $B\left(\mathrm{~g} \mathrm{mg}^{-1}\right)$ are elovich constants.

The experimental data of kinetic parameters are summarized in Table 2. The highest correlation coefficient, $R^{2}$, was found in pseudo-second order (0.998) as compared to pseudo-first order. The calculated adsorption capacity $q_{\mathrm{e}}^{\text {cal }}$ $\left(\mathrm{mgg}^{-1}\right)$ from pseudo-second-order model represents a good agreement with the experimental adsorption capacity $q_{\mathrm{e}}^{\exp }$ as shown in Fig. 10a-d. This indicated that pseudo-secondorder model was the best fitted kinetic model for the adsorption of $\mathrm{CV}$ dye onto PGADP and the rate limiting step may be chemisorption. The adsorption rate of dye onto the surface of PGADP might be controlled by complexation and coordination because the large number of functional groups present in the material of PGADP (Niu et al. 2017). From kinetic model of intra-particle diffusion, indicated increased boundary layer effect by increase in the value of $C$ (constant) with increasing concentration of CV dye (Kratochvil 1998; Ghodbane and Hamdaoui 2008). The plots of $q_{\mathrm{t}}$ against $t^{1 / 2}$ for different concentration of $\mathrm{CV}$ dye showed deviation from origin indicated that intra-particle diffusion not the only the rate controlling step but some other mechanism for example surface adsorption, film diffusion and pore diffusion might
Table 2 Kinetics parameters for the adsorption of crystal violet dye on PGADP

\begin{tabular}{lllll}
\hline Model & Parameters & \multicolumn{3}{l}{ Concentration $\left(\mathrm{mg} \mathrm{L}^{-1}\right)$} \\
\cline { 3 - 5 } & & 20 & 50 & 100 \\
\hline Pseudo-first Order & $q_{\mathrm{e}}(\mathrm{exp})\left(\mathrm{mg} \mathrm{g}^{-1}\right)$ & 14.854 & 36.242 & 64.121 \\
& $q_{\mathrm{e}}(\mathrm{cal})\left(\mathrm{mg} \mathrm{g}^{-1}\right)$ & 3.532 & 9.120 & 14.962 \\
& $k_{1}\left(\mathrm{~min}^{-1}\right)$ & 0.016 & 0.016 & 0.014 \\
& $R^{2}$ & 0.986 & 0.982 & 0.939 \\
Pseudo-second order & $q_{\mathrm{e}}(\mathrm{exp})\left(\mathrm{mg} \mathrm{g}^{-1}\right)$ & 14.854 & 36.242 & 64.121 \\
& $q_{\mathrm{e}}(\mathrm{cal})\left(\mathrm{mg} \mathrm{g}^{-1}\right)$ & 14.992 & 36.630 & 64.516 \\
& $k_{2}\left(\mathrm{~g} \mathrm{mg}^{-1} \mathrm{~min}^{-1}\right)$ & 0.018 & 0.007 & 0.004 \\
Intra-particle diffu- & $R^{2}$ & 0.998 & 0.998 & 0.998 \\
sion & $K_{\mathrm{id}}\left(\mathrm{mg} \mathrm{g}^{-1} \mathrm{~min}^{-1 / 2}\right)$ & 0.314 & 0.797 & 1.339 \\
& $I$ & 10.867 & 26.047 & 46.685 \\
Elovich & $R^{2}$ & 0.970 & 0.974 & 0.966 \\
& $A\left(\mathrm{mg} \mathrm{g}^{-1} \mathrm{~min}^{-1}\right)$ & 9.525 & 22.750 & 41.186 \\
& $B\left(\mathrm{~g} \mathrm{mg}^{-1}\right)$ & 1.002 & 2.512 & 4.209 \\
& $R^{2}$ & 0.976 & 0.956 & 0.944 \\
\hline
\end{tabular}

also be involved in the adsorption process (Zhang et al. 2016).

\section{Effect of initial dye concentration and adsorption isotherm}

The effect of the initial dye concentration $\left(20-100 \mathrm{mgL}^{-1}\right)$ was examined by treating $0.025 \mathrm{~g}$ (dose), $7.3(\mathrm{pH}), 180 \mathrm{~min}$ (contact time) and temperature (303-323 K), respectively. As shown in Fig. 11, the adsorption capacity increases with increase in initial concentration at all temperature that might be due to increased concentration gradient between the bulk solution and the adsorbent surface (Tünay et al. 1996).

The adsorption isotherm model gives the information about the optimization of the adsorption reactions (Hasan and Ahamd 2019). The equilibrium data were elucidated using four isotherm models namely, Langmuir, Freundlich, Temkin and Dubinin-Radushkevich (D-R) isotherm models. Eqs. (7-10) for these models are represented as:

$\frac{1}{q_{\mathrm{e}}}=\frac{1}{C_{\mathrm{e}} \cdot b q_{\mathrm{m}}}+\frac{1}{q_{\mathrm{m}}}$

$\log q_{\mathrm{e}}=\log K_{\mathrm{F}}+\frac{1}{n} \log C_{\mathrm{e}}$

$q_{\mathrm{e}}=B \ln A+B \ln C_{\mathrm{e}}$

$\ln q_{\mathrm{e}}=\ln q_{\mathrm{m}}-\beta \varepsilon^{2}$

where $q_{\mathrm{e}}$ and $q_{\mathrm{m}}$ are the adsorption capacity $\left(\mathrm{mgg}^{-1}\right)$ at equilibrium and monolayer adsorption capacity $\left(\mathrm{mgg}^{-1}\right)$. 

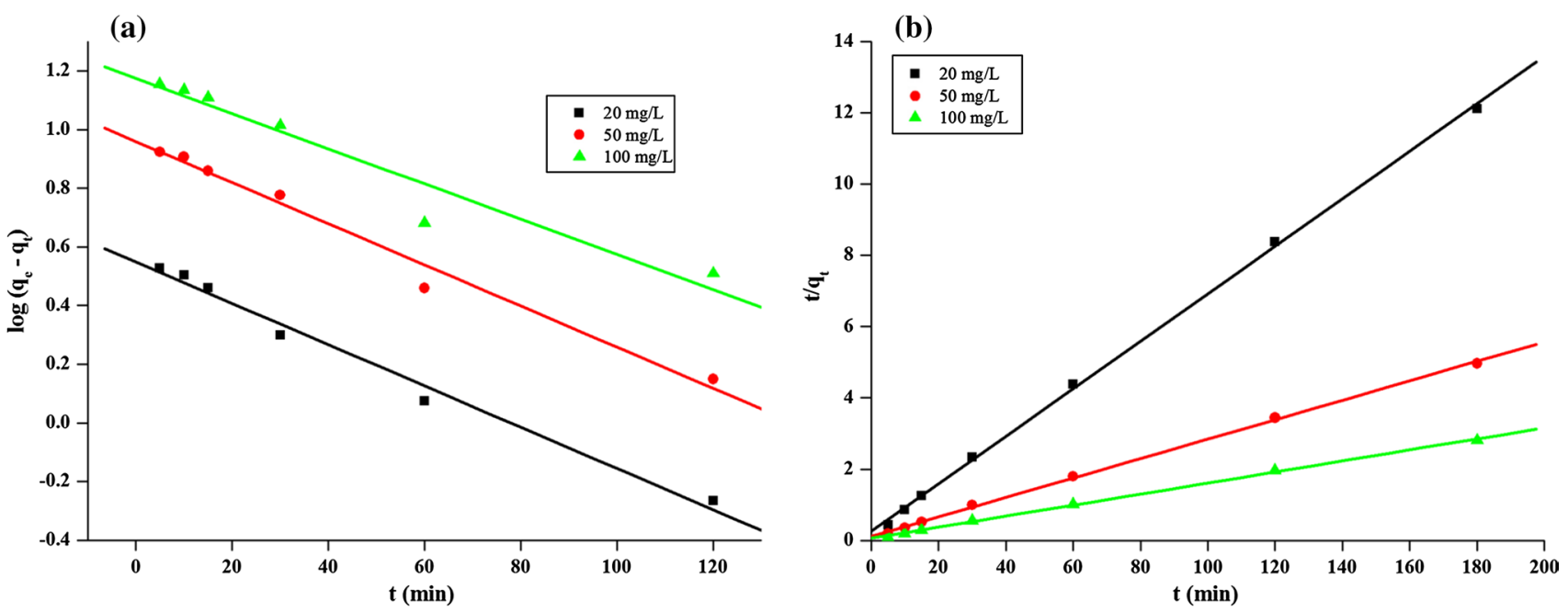

(c)

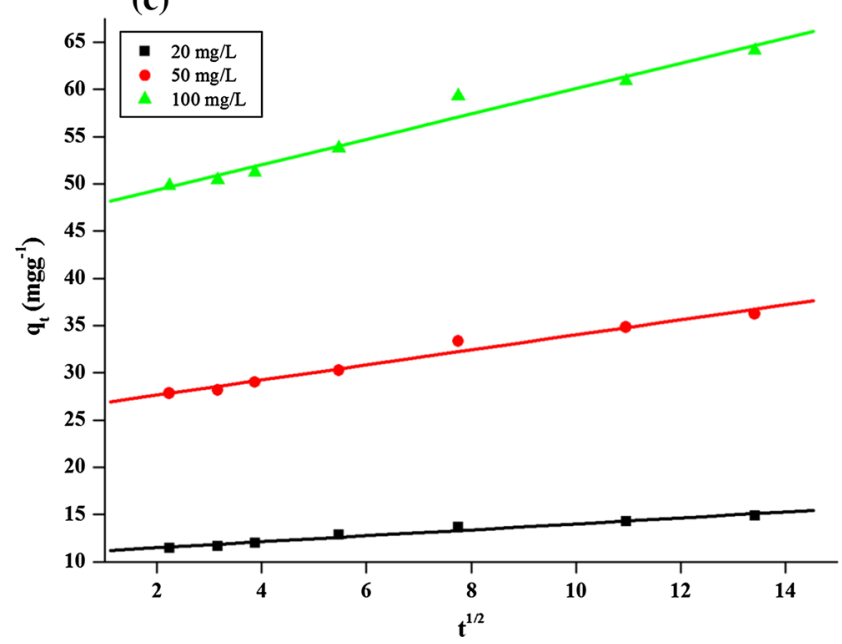

(d)

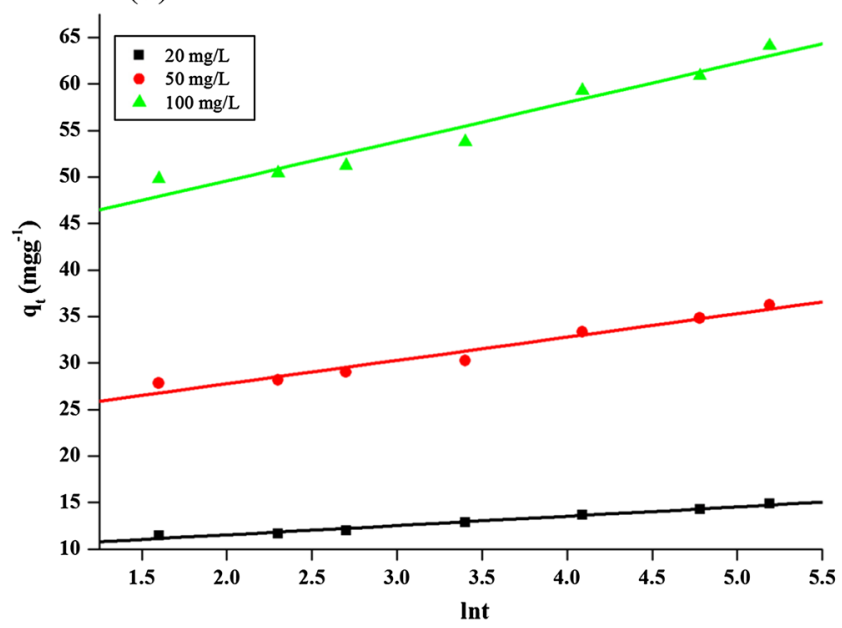

Fig. 10 Adsorption kinetics a pseudo-first order b pseudo-second order $\mathbf{c}$ Intra-particle diffusion (d) Elovich for the adsorption of CV onto PGADP at different concentration

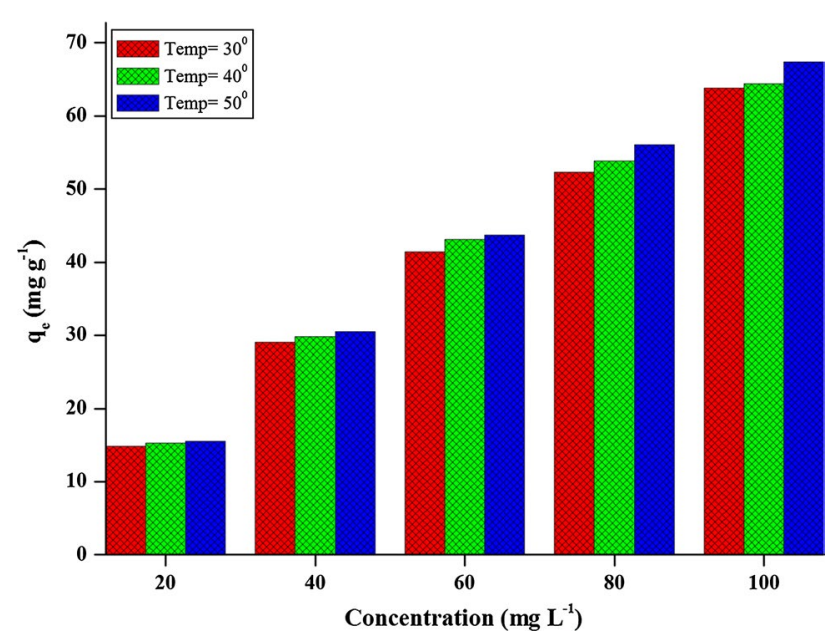

Fig. 11 Effect of initial dye concentration on the adsorption of $\mathrm{CV}$ onto PGADP (conditions; $\mathrm{pH}=7.3$; adsorbent $=0.025 \mathrm{~g}$; contact time $=180 \mathrm{~min}$ )
$C_{\mathrm{e}}$ is the adsorbate equilibrium concentration $\left(\mathrm{mg} \mathrm{L}^{-1}\right)$ and $b$ is the constant related to adsorption energy $\left(\mathrm{Lmg}^{-1}\right)$. $K_{\mathrm{F}}\left(\left(\mathrm{mgg}^{-1}\right)\left(\mathrm{Lmg}^{-1}\right)^{1 / n}\right)$ is the Freundlich isotherm constant, $n$ is the indication of adsorption intensity. $A\left(\mathrm{mgL}^{-1}\right)$ and $B$ $\left(\mathrm{J} \mathrm{mol}^{-1}\right)$ are Temkin constants related to the equilibrium binding constant and the heat of adsorption, respectively. $\beta$ $\left(m o l \mathrm{~K}^{-2} \mathrm{~J}^{-2}\right)$ is the isotherm constant related to parameter $E$ (mean free energy per molecule of adsorbate) $\left(\mathrm{kJ} \mathrm{mol}^{-1}\right)$, and $\varepsilon$ is the polanyi potential related to $C_{\mathrm{e}}$, respectively, determined in Eqs. (11-12)

$E=\frac{1}{\sqrt{2 \beta}}$

$\varepsilon=R T\left(1+1 / C_{\mathrm{e}}\right)$ 
Table 3 Adsorption isotherm parameters for adsorption of crystal violet dye on PGADP at 30,40 and $50^{\circ} \mathrm{C}$

\begin{tabular}{lllll}
\hline Model & Parameters & \multicolumn{2}{l}{ Temperature } & \\
\cline { 3 - 4 } & & $30{ }^{\circ} \mathrm{C}$ & $40{ }^{\circ} \mathrm{C}$ & $50{ }^{\circ} \mathrm{C}$ \\
\hline Langmuir & $b\left(\mathrm{~L} \mathrm{~g}^{-1}\right)$ & 0.173 & 0.295 & 0.447 \\
& $q_{\mathrm{m}}\left(\mathrm{mg} \mathrm{g}^{-1}\right)$ & 75.188 & 70.422 & 69.930 \\
& $R^{2}$ & 0.998 & 0.996 & 0.994 \\
Freundlich & $K_{\mathrm{F}}\left(\mathrm{mg} \mathrm{g}^{-1)}\left(\mathrm{L} \mathrm{mg}^{-1}\right)^{1 / n}\right.$ & 13.182 & 16.982 & 20.417 \\
& $n$ & 1.883 & 2.164 & 2.257 \\
& $R^{2}$ & 0.986 & 0.978 & 0.982 \\
Temkin & $A\left(\mathrm{~L} \mathrm{~g}^{-1}\right)$ & $0.54 \times 10^{2}$ & $26.82 \times 10^{4}$ & $95.20 \times 10^{6}$ \\
& $B\left(\mathrm{~J} \mathrm{~mol}^{-1}\right)$ & 17.691 & 15.809 & 15.619 \\
& $R^{2}$ & 0.980 & 0.992 & 0.984 \\
& $q_{\mathrm{m}}\left(\mathrm{mol} \mathrm{g}^{-1}\right)$ & 117.92 & 81.451 & 69.408 \\
& $\beta\left(\mathrm{mol} \mathrm{K}^{-2} \mathrm{~J}^{-2}\right)$ & $11.68 \times 10^{-8}$ & $5.961 \times 10^{-8}$ & $3.275 \times 10^{-8}$ \\
& $E\left(\mathrm{~kJ} \mathrm{~mol}^{-1}\right)$ & 2.069 & 2.896 & 3.908 \\
& $R^{2}$ & 0.925 & 0.908 & 0.889 \\
\hline
\end{tabular}

where $R\left(8.314 \mathrm{~J} \mathrm{~mol}^{-1} \mathrm{~K}^{-1}\right)$ and $T(\mathrm{~K})$ are the gas constant and absolute temperature, respectively, (Foo and Hameed 2010).

The results of various isotherm models are tabulated in Table 3. Based on high correlation coefficient value $\left(R^{2}\right)$ as can be observed from Fig. $12 \mathrm{a}-\mathrm{d}$, the Langmuir isotherm model fitted best with the equilibrium adsorption data refers to monolayer coverage of $\mathrm{CV}$ dye on the specific homogenous sites of PGADP. The plot of $\log q_{\mathrm{e}}$ versus $\log C_{\mathrm{e}}$ in Freundlich gives straight line at different temperatures. Freundlich isotherm model is used for the identification of the surface heterogeneity of adsorbent and gives the details of interaction between adsorbate and the active sites of the adsorbent with the large range of adsorbate concentrations (Sharifnia et al. 2016). The obtained value of $n$ greater than 1 , at all temperature indicates that the adsorption of $\mathrm{CV}$ dye onto the surface of PGADP was favorable by positive binding because if $n^{>} 1$, then adsorption indicates favorable condition. Temkin model describe that heat of adsorption is assumed to be decreased linearly with coverage. The values of constant $A$ and $B$ were obtained from the plot of $q_{\mathrm{e}}$ versus $\ln C_{\mathrm{e}}$ which represents binding energy and enthalpy of adsorption, respectively. Increasing the value of constant A with increased in temperature signifies strong binding of adsorbate and adsorbent at a higher temperature. Dubinin-Radushkevich isotherm is generally used to described the mechanism of adsorption with respect to Gaussian energy distribution onto a heterogeneous surface and determine the nature of adsorption as physical or chemical based on the free mean sorption energy (Da̧browski 2001; Rao and Rehman 2010). The value of free mean energy, E, was obtained less than $8\left(\mathrm{~kJ} \mathrm{~mol}^{-1}\right)$ at all temperature suggesting physical adsorption occurs of $\mathrm{CV}$ dye at the surface of the PGADP (Anayurt et al. 2009).

\section{Thermodynamic study}

The thermodynamic parameters like free energy change $\left(\Delta G^{\circ}\right)$, enthalpy change $\left(\Delta H^{\circ}\right)$ and entropy change $\left(\Delta S^{\circ}\right)$ for the adsorption of $\mathrm{CV}$ dye onto the surface of PGADP were calculated from the following Eqs. (13-15):

$K_{\mathrm{c}}=\frac{\left(C_{\mathrm{i}}-C_{\mathrm{e}}\right)}{C_{\mathrm{e}}}$

$\Delta G^{\circ}=-R T \ln K_{\mathrm{c}}$

$\log K_{\mathrm{c}}=\frac{\Delta S^{\circ}}{2.303 R}-\frac{\Delta H^{\circ}}{2.303 R T}$

where $C_{\mathrm{i}}$ and $C_{\mathrm{e}}$ were the initial concentration and concentration at equilibrium time $\left(\mathrm{mgL}^{-1}\right) . T$ is the temperature $(\mathrm{K}), K_{\mathrm{c}}$ is the distribution coefficient, and $R\left(\mathrm{JK}^{-1} \mathrm{~mol}^{-1}\right)$ is the universal gas constant, respectively. The thermodynamic parameters like $\Delta H^{\circ}$ and $\Delta S^{\circ}$ were evaluated using the plot of $\log K_{\mathrm{c}}$ versus $1 / T$, and values are summarized in Table 4 and shown in Fig. 13. The negative values of $\Delta G^{\circ}$ for adsorption of $\mathrm{CV}$ dye onto the surface of PGADP indicate the feasibility and spontaneous nature of adsorption and the negative $\Delta G^{\circ}$ values obtained lower than -20 $\left(\mathrm{kJ} \mathrm{mol}^{-1}\right)$ at all temperature signifying physical adsorption (Huang et al. 2014). The positive values of $\Delta H^{\circ}$ and $\Delta S^{\circ}$ confirm the endothermic nature of adsorption and reflect the affinity of PGADP for CV and also show the increased randomness at the solid-solution interface. 

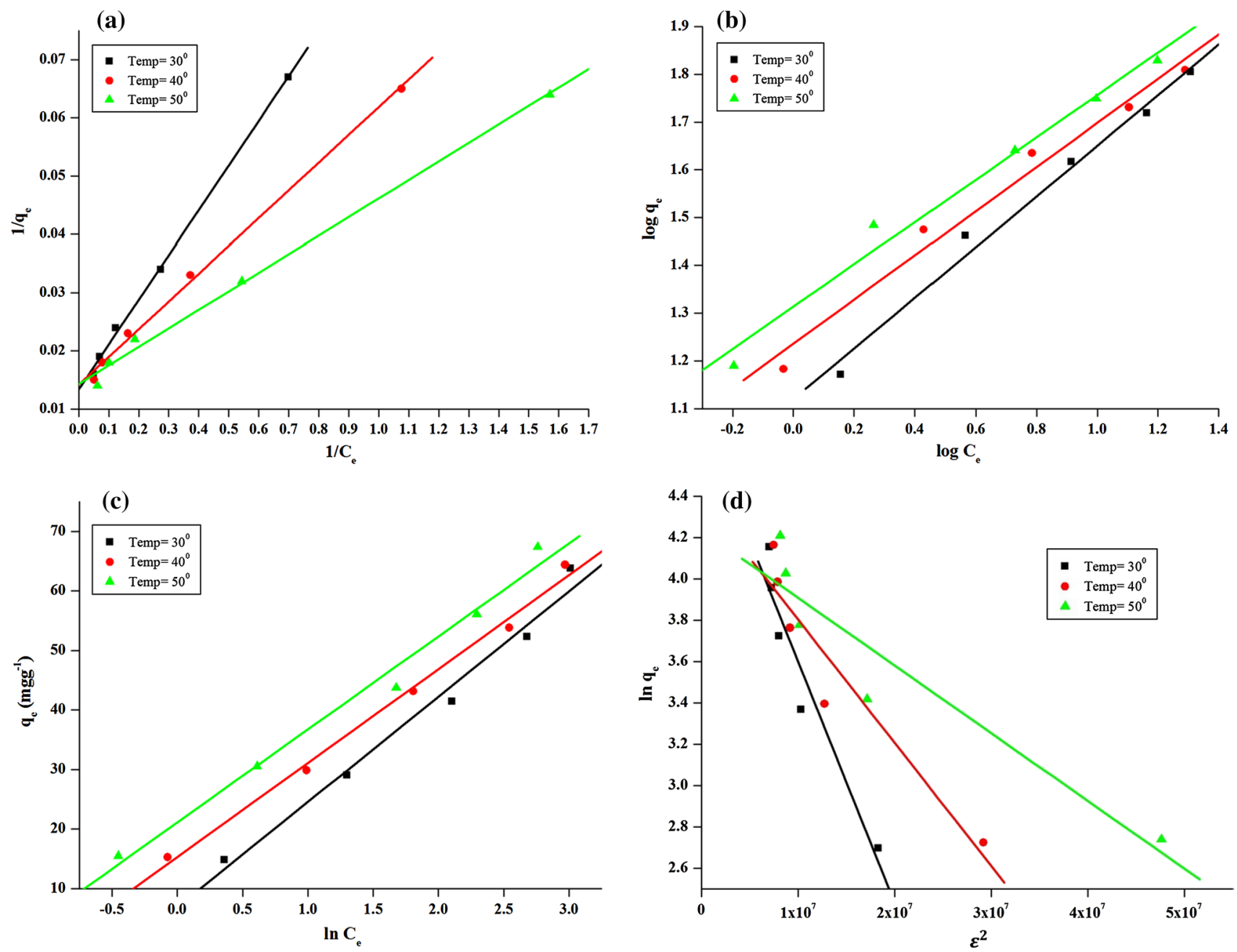

Fig. 12 Adsorption isotherm a Langmuir b Freundlich $\mathbf{c}$ Temkin d D-R model for the adsorption of CV onto PGADP at different temperature

Table 4 Thermodynamic parameters for the adsorption of crystal violet dye on PGADP at different temperatures

\begin{tabular}{lllll}
\hline $\begin{array}{l}\text { Tem- } \\
\text { perature } \\
\left({ }^{\circ} \mathrm{C}\right)\end{array}$ & $K_{\mathrm{c}}$ & $\begin{array}{l}\Delta H^{\circ}(\mathrm{KJ} \\
\left.\mathrm{mol}^{-1}\right)\end{array}$ & $\begin{array}{l}\Delta G^{\circ}(\mathrm{KJ} \\
\left.\mathrm{mol}^{-1}\right)\end{array}$ & $\begin{array}{l}\Delta S^{\circ}\left(\mathrm{KJ} \mathrm{mol}^{-1}\right. \\
\left.\mathrm{K}^{-1}\right)\end{array}$ \\
\hline 30 & 12.966 & 36.092 & -6.454 & 0.140 \\
40 & 20.528 & & -7.861 & \\
50 & 30.847 & & -9.208 & \\
\hline
\end{tabular}

\section{Adsorption mechanism}

To comprehend the mechanism of the interaction between functionalized PGADP and molecules of CV dye, a number of different spectroscopic techniques such as FTIR and EDX were used. The interaction between adsorbate-adsorbent depends on the chemistry of adsorbate, solution $\mathrm{pH}$, chemical and physical nature of adsorbent. At lower

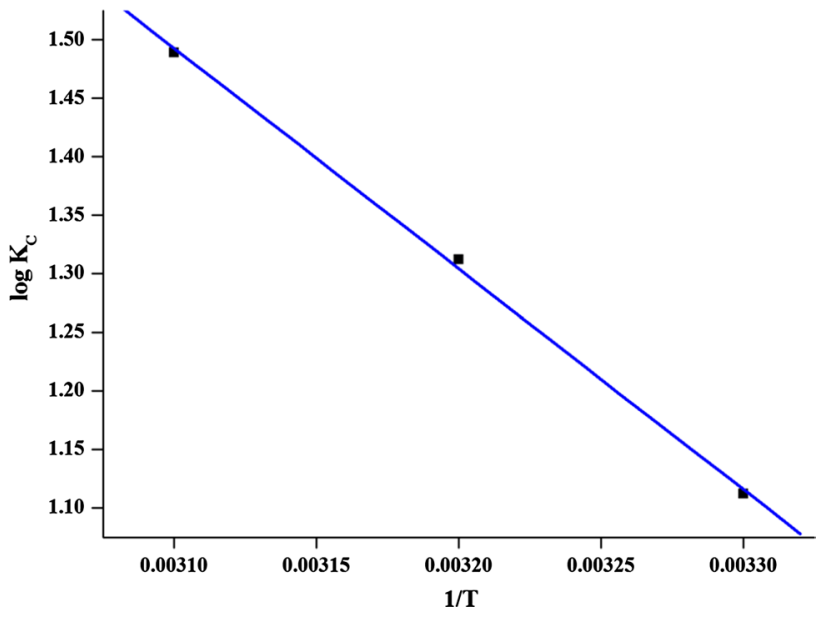

Fig. 13 Adsorption thermodynamics for the adsorption of $\mathrm{CV}$ onto PGADP 
$\mathrm{pH}$, the $-\mathrm{NH}_{2}$ and $-\mathrm{OH}$ functional groups of negatively charged adsorbent PGADP have a strong coordinative affinity toward CV dye by surface complexation through electrostatic interaction, while this affinity decreases at higher $\mathrm{pH}$ as due to repulsive force between positively charged cationic dye ions and lone pairs of the $-\mathrm{NH}_{2}$ and -OH groups of PGADP. The Dubinin-Radushkevich isotherm results show that the mechanism of adsorption with respect to Gaussian energy distribution onto a heterogeneous surface and determined based on the free mean sorption energy physical adsorption occurs on the surface of PGADP. After the adsorption of CV dye, some changes in the absorption wave numbers and also the intensities of absorption bands of the adsorbent were observed. Indeed, slight shifts in the peak positions were observed in the regions $2832-2844$ and $1646-1658 \mathrm{~cm}^{-1}$ which are probably due to the removal of CV over PGADP via a strong hydrogen bonds and electrostatic interactions between ions of the dye molecules with the $-\mathrm{NH}_{2}$ and $-\mathrm{OH}$ groups of PGADP.

\section{Breakthrough studies}

Breakthrough capacity can be used to determine the concentration gradient between the solute adsorbed by the adsorbent and remaining in the solution (Rao et al. 2016). Breakthrough studies were carried out by column process. $0.05 \mathrm{~g}$ of adsorbent was accurately weighed and transfer in a glass wool supported column ( $0.6 \mathrm{~cm}$ i.d.). $250 \mathrm{~mL}$ solution of $\mathrm{CV}$ dye with initial concentration $20 \mathrm{mgL}^{-1}$ was taken in a column and passed with flow rate of $1 \mathrm{mLmin}^{-1}$. The effluent was collected in $10 \mathrm{~mL}$ fraction and examined by UV/VIS spectrophotometer. The breakthrough

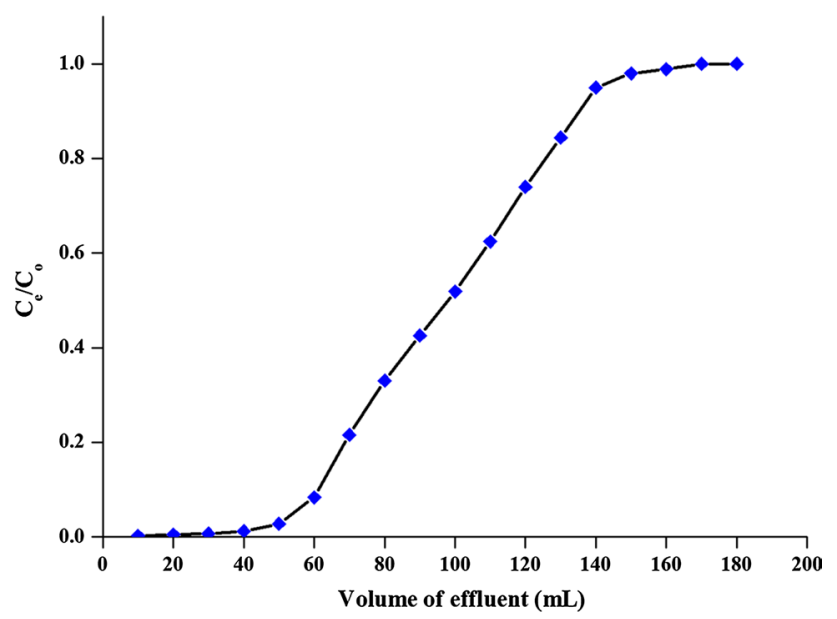

Fig. 14 Breakthrough curve (conditions; adsorbent $=0.05 \mathrm{~g} ; \mathrm{CV}=20$ $\mathrm{mgL}^{-1}$; flow rate $=1 \mathrm{~mL} \mathrm{~min}^{-1}$ ) curve plotted between the $\left(C_{\mathrm{e}} / C_{\mathrm{o}}\right)$ versus volume of effluent $(\mathrm{mL})$ is shown in Fig. 14. As seen from breakthrough curve, $40 \mathrm{~mL}$ solution of $\mathrm{CV}$ dye could flow down the column without being detected in the effluent. From the breakthrough experiment by using column process, the breakthrough capacity was found to be $16\left(\mathrm{mgg}^{-1}\right)$ while exhaustive capacity was determined as $68\left(\mathrm{mgg}^{-1}\right)$.

\section{Desorption and regeneration}

The desorption study of CV dye was carried out by batch adsorption process using several reagents. After the attainment of equilibrium time, adsorbent was filtered and subsequently washed several times with double distilled water. The washed adsorbent was transferred into a conical flask containing $1 \mathrm{M}$ acetic acid $\left(\mathrm{CH}_{3} \mathrm{COOH}\right)$ solution, and the mixture was left for 24 hat room temperature. The result showed that the maximum desorption of $\mathrm{CV}$ dye was $89 \%$ in $1 \mathrm{M} \mathrm{CH}_{3} \mathrm{COOH}$ solution (Fig. 15). The \% desorption decreases up to $45 \%$ in fourth cycle as the number of cycles increased. Therefore, the adsorbent can be reused up to fourth cycle successfully.

\section{Comparison of monolayer adsorption capacity $\left(q_{m}\right)$}

The monolayer adsorption capacity of PGADP onto CV dye was compared by other adsorbents from the literature, and the results are reported in Table 5. It is clearly evident from Table that the present PGADP adsorbents have better adsorption capacity as compared to the other adsorbents for the removal of CV dye. This suggests that the PGADP material has great prospective in practical applications for the enhanced removal of $\mathrm{CV}$ dye from aqueous solution and industrial waste water.

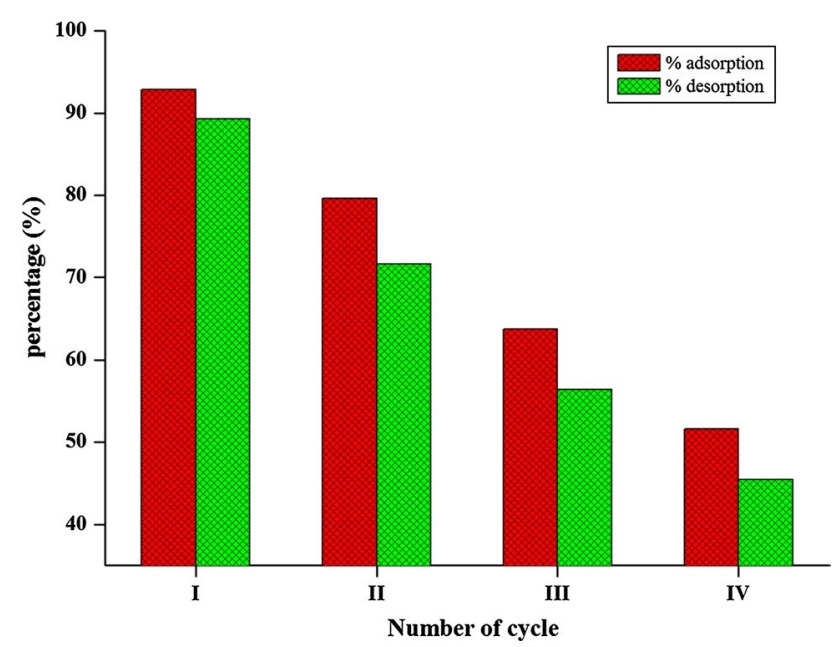

Fig. 15 Regeneration of PGADP by batch mode (conditions; adsorbent $=0.025 \mathrm{~g} ; \mathrm{CV}=20 \mathrm{mgL}^{-1}$; cycles $=4$ ) 
Table 5 Comparison of crystal violet adsorption capacity with various adsorbents

\begin{tabular}{llll}
\hline Sr. No. & Adsorbents & $q_{\max }\left(\mathrm{mgg}^{-1}\right)$ & References \\
\hline 1 & Coniferous pinus bark & 32.78 & Ahmad (2009) \\
2 & NaOH Modified Rice husk & 44.90 & Chakraborty et al. (2011) \\
3 & Grafted sodium alginate/ZnO/graphene & 13.85 & Mohamed et al. (2017) \\
& $\quad$ oxide composite & & \\
4 & Biosilica/alginate nanobiocomposite & 21.32 & Taylor et al. (2014) \\
5 & Rice bran & 42.25 & Malik and Sanyal (2004) \\
6 & Chitin nanowhiskers (ChNW) & 39.56 & Gopi et al. (2016) \\
7 & Treated ginger waste & 64.93 & Kumar and Ahmad (2011) \\
8 & Polyacrylamide-grafted Actinidia deli- & 75.19 & This study \\
& ciosa peels powder (PGADP) & & \\
\hline
\end{tabular}

\section{Conclusion}

In this wok, a novel and eco-friendly low-cost adsorbent polyacrylamide-grafted Actinidia deliciosa peels powder (PGADP) has been successfully synthesized and further explored as a potential adsorbent for the sequestration of crystal violet dye (CV) from aqueous solution. The maximum adsorption of $\mathrm{CV}$ dye from aqueous solution was observed at $\mathrm{pH} 7.3$, contact time $180 \mathrm{~min}$, initial dye concentration $20 \mathrm{mgL}^{-1}$. The kinetic data showed that pseudosecond order model was best obeyed over a wide range of concentrations. The equilibrium data were best fitted to Langmuir isotherm with maximum coefficient of $\left(R^{2}, 0.998\right)$ at $30^{\circ} \mathrm{C}$. In thermodynamic study, positive value of $\Delta \mathrm{H}^{\circ}$ and negative value of $\Delta G^{\circ}$ confirms endothermic and spontaneous nature of adsorption process with increased randomness at solid-solution interface with increase in temperature. Desorption study showed that $89 \%$ of adsorbed CV dye could be desorbed successfully by using $1 \mathrm{M}$ Acetic acid. To make the process more economical, the exhausted adsorbent was further regenerated and it was observed that it can be regenerated up to fourth cycle without significant loss in capacity. Therefore, the present material can be utilized to treat the waste water economically in developing countries at large scale.

Acknowledgements The authors greatly acknowledge the Chairman, Department of Applied Chemistry, AMU for research facility; USIF, AMU; Department of Chemistry for XRD and TGA facility.

Funding One of the authors (Mr. Khalid Ansari) is highly thankful to UGC-New Delhi for providing financial assistance.

\section{Compliance with ethical standards}

Conflict of interest The authors declare that they do not have any conflict of interest.

Open Access This article is licensed under a Creative Commons Attribution 4.0 International License, which permits use, sharing, adaptation, distribution and reproduction in any medium or format, as long as you give appropriate credit to the original author(s) and the source, provide a link to the Creative Commons licence, and indicate if changes were made. The images or other third party material in this article are included in the article's Creative Commons licence, unless indicated otherwise in a credit line to the material. If material is not included in the article's Creative Commons licence and your intended use is not permitted by statutory regulation or exceeds the permitted use, you will need to obtain permission directly from the copyright holder. To view a copy of this licence, visit http://creativecommons.org/licenses/by/4.0/.

\section{References}

Abdolali A, Ngo HH, Guo W (2015) Characterization of a multi-metal binding biosorbent: chemical modification and desorption studies. Biores Technol 193:477-487. https://doi.org/10.1016/j.biort ech.2015.06.123

Ahmad R (2009) Studies on adsorption of crystal violet dye from aqueous solution onto coniferous pinus bark powder (CPBP). J Hazard Mater 171:767-773. https://doi.org/10.1016/j.jhazm at.2009.06.060

Ahmad R, Mirza A (2017) Adsorption of $\mathrm{Pb}(\mathrm{II})$ and $\mathrm{Cu}(\mathrm{II})$ by Alginate-Au-Mica bionanocomposite: kinetic, isotherm and thermodynamic studies. Process Saf Environ Prot 109:1-10. https://doi. org/10.1016/j.psep.2017.03.020

Ajmal M, Khan Rao RA, Siddiqui BA (1996) Studies on removal and recovery of $\mathrm{Cr}(\mathrm{VI})$ from electroplating wastes. Water Res 30:1478-1482. https://doi.org/10.1016/0043-1354(95)00301-0

Ali Khan Rao R, Khatoon A (2017) Sorption studies for Cd(II) sequestration from aqueous solution on chemically modified Albizia lebbeck. Separ Sci Technol (Philadelphia) 52:435-446. https://doi. org/10.1080/01496395.2016.1213285

Anayurt RA, Sari A, Tuzen M (2009) Equilibrium, thermodynamic and kinetic studies on biosorption of $\mathrm{Pb}$ (II) and $\mathrm{Cd}(\mathrm{II})$ from aqueous solution by macrofungus (Lactarius scrobiculatus) biomass. Chem Eng J 151:255-261. https://doi.org/10.1016/j.cej.2009.03.002

Bizani E, Fytianos K, Poulios I, Tsiridis V (2006) Photocatalytic decolorization and degradation of dye solutions and wastewaters in the presence of titanium dioxide. J Hazard Mater 136:85-94. https:// doi.org/10.1016/j.jhazmat.2005.11.017

Chakraborty S, Chowdhury S, Das Saha P (2011) Adsorption of Crystal Violet from aqueous solution onto $\mathrm{NaOH}$-modified rice husk. Carbohyd Polym 86:1533-1541. https://doi.org/10.1016/j.carbp ol.2011.06.058 
Dą̧browski A (2001) Adsorption-from theory to practice. Adv Coll Interface Sci 93:135-224. https://doi.org/10.1016/S0001 -8686(00)00082-8

Foo KY, Hameed BH (2010) Insights into the modeling of adsorption isotherm systems. Chem Eng J 156:2-10. https://doi. org/10.1016/j.cej.2009.09.013

Franco DSP, Piccin JS, Lima EC, Dotto GL (2015) Interpretations about methylene blue adsorption by surface modified chitin using the statistical physics treatment. Adsorption 21:557-564. https:// doi.org/10.1007/s10450-015-9699-z

Gao M, Ma Q, Lin Q et al (2015) Combined modification of fly ash with $\mathrm{Ca}(\mathrm{OH})_{2} / \mathrm{Na}_{2} \mathrm{FeO}_{4}$ and its adsorption of Methyl orange. Appl Surf Sci 359:323-330. https://doi.org/10.1016/j.apsus c. 2015.10 .135

Georgin J, Marques BS, Peres EC et al (2018) Biosorption of cationic dyes by Pará chestnut husk (Bertholletia excelsa). Water Sci Technol 77:1612-1621. https://doi.org/10.2166/wst.2018.041

Ghodbane I, Hamdaoui O (2008) Removal of mercury(II) from aqueous media using eucalyptus bark: kinetic and equilibrium studies. J Hazard Mater 160:301-309. https://doi.org/10.1016/j.jhazm at.2008.02.116

Gopalakannan V, Viswanathan N (2015) Synthesis of magnetic alginate hybrid beads for efficient chromium (VI) removal. Int J Biol Macromol 72:862-867. https://doi.org/10.1016/j.ijbio mac.2014.09.024

Gopi S, Pius A, Thomas S (2016) Enhanced adsorption of crystal violet by synthesized and characterized chitin nano whiskers from shrimp shell. J Water Process Eng 14:1-8. https://doi. org/10.1016/j.jwpe.2016.07.010

Gupta VK, Suhas (2009) Application of low-cost adsorbents for dye removal-a review. J Environ Manag 90:2313-2342. https://doi. org/10.1016/j.jenvman.2008.11.017

Hasan I, Ahamd R (2019) A facile synthesis of poly (methyl methacrylate) grafted alginate@Cys-bentonite copolymer hybrid nanocomposite for sequestration of heavy metals. Groundwater Sustain Dev 8:82-92. https://doi.org/10.1016/j.gsd.2018.09.003

Hassani A, Soltani RDC, Karaca S, Khataee A (2015) Preparation of montmorillonite-alginate nanobiocomposite for adsorption of a textile dye in aqueous phase: isotherm, kinetic and experimental design approaches. J Ind Eng Chem 21:1197-1207. https://doi. org/10.1016/j.jiec.2014.05.034

Hossain MA, Ngo HH, Guo WS et al (2014) Performance of cabbage and cauliflower wastes for heavy metals removal. Desalinat Water Treat 52:844-860. https://doi.org/10.1080/19443 994.2013.826322

Huang Y, Li S, Chen J et al (2014) Adsorption of $\mathrm{Pb}$ (II) on mesoporous activated carbons fabricated from water hyacinth using $\mathrm{H}_{3} \mathrm{PO}_{4}$ activation: adsorption capacity, kinetic and isotherm studies. Appl Surf Sci 293:160-168. https://doi.org/10.1016/j.apsus c. 2013.12 .123

Ibhadon AO, Greenway GM, Yue Y (2008) Photocatalytic activity of surface modified $\mathrm{TiO}_{2} / \mathrm{RuO}_{2} / \mathrm{SiO}_{2}$ nanoparticles for azo-dye degradation. Catal Commun 9:153-157. https://doi.org/10.1016/j. catcom.2007.05.038

Jayasantha Kumari H, Krishnamoorthy P, Arumugam TK et al (2017) An efficient removal of crystal violet dye from waste water by adsorption onto TLAC/Chitosan composite: a novel low cost adsorbent. Int J Biol Macromol 96:324-333. https://doi. org/10.1016/j.ijbiomac.2016.11.077

Kausar A, Iqbal M, Javed A et al (2018) Dyes adsorption using clay and modified clay: a review. J Mol Liq 256:395-407. https://doi. org/10.1016/j.molliq.2018.02.034

Konicki W, Sibera D, Mijowska E et al (2013) Equilibrium and kinetic studies on acid dye Acid Red 88 adsorption by magnetic $\mathrm{ZnFe}_{2} \mathrm{O}_{4}$ spinel ferrite nanoparticles. J Colloid Interface Sci 398:152-160. https://doi.org/10.1016/j.jcis.2013.02.021
Kratochvil D (1998) Advances in the biosorption of heavy metals. Trends Biotechnol 16:291-300. https://doi.org/10.1016/S0167 -7799(98)01218-9

Kumar R, Ahmad R (2011) Biosorption of hazardous crystal violet dye from aqueous solution onto treated ginger waste (TGW). Desalination 265:112-118. https://doi.org/10.1016/j.desal.2010.07.040

Li FT, Yang H, Zhao Y, Xu R (2007) Novel modified pectin for heavy metal adsorption. Chin Chem Lett 18:325-328. https://doi. org/10.1016/j.cclet.2007.01.034

Ma Y, Liu WJ, Zhang N et al (2014) Polyethylenimine modified biochar adsorbent for hexavalent chromium removal from the aqueous solution. Biores Technol 169:403-408. https://doi.org/10.1016/j. biortech.2014.07.014

Malik PK, Sanyal SK (2004) Kinetics of decolourisation of azo dyes in wastewater by $\mathrm{UV} / \mathrm{H}_{2} \mathrm{O}_{2}$ process. Science $36: 167-175$. https:// doi.org/10.1016/S1383-5866(03)00212-0

Martins LR, Rodrigues JAV, Adarme OFH et al (2017) Optimization of cellulose and sugarcane bagasse oxidation: application for adsorptive removal of crystal violet and auramine-O from aqueous solution. J Colloid Interface Sci 494:223-241. https://doi. org/10.1016/j.jcis.2017.01.085

Meili L, da Silva TS, Henrique DC et al (2017) Ouricuri (Syagrus coronata) fiber: a novel biosorbent to remove methylene blue from aqueous solutions. Water Sci Technol 75:106-114. https:// doi.org/10.2166/wst.2016.495

Mirza A, Ahmad R (2020) An efficient sequestration of toxic crystal violet dye from aqueous solution by Alginate/Pectin nanocomposite: a novel and ecofriendly adsorbent. Ground Water Sustain Dev 11:100373. https://doi.org/10.1016/j.gsd.2020.100373

Mohamed SK, Hegazy SH, Abdelwahab NA, Ramadan AM (2017) Coupled adsorption-photocatalytic degradation of crystal violet under sunlight using chemically synthesized grafted sodium alginate/ZnO/Graphene oxide composite. Int J Biol Macromol. https ://doi.org/10.1016/j.ijbiomac.2017.11.028

Niu Y, Li K, Ying D et al (2017) Novel recyclable adsorbent for the removal of copper(II) and lead(II) from aqueous solution. Biores Technol 229:63-68. https://doi.org/10.1016/j.biort ech.2017.01.007

Osma JF, Saravia V, Toca-Herrera JL, Couto SR (2007) Sunflower seed shells: a novel and effective low-cost adsorbent for the removal of the diazo dye Reactive Black 5 from aqueous solutions. J Hazard Mater 147:900-905. https://doi.org/10.1016/j. jhazmat.2007.01.112

Pang X, Sellaoui L, Franco D et al (2019) Adsorption of crystal violet on biomasses from pecan nutshell, para chestnut husk, araucaria bark and palm cactus: experimental study and theoretical modeling via monolayer and double layer statistical physics models. Chem Eng J. https://doi.org/10.1016/j.cej.2019.122101

Rao RAK, Rehman F (2010) Adsorption of heavy metal ions on pomegranate (punica granatum) peel: removal and recovery of $\mathrm{Cr}(\mathrm{VI})$ ions from a multi-metal ion system. Adsorpt Sci Technol 28:195211. https://doi.org/10.1260/0263-6174.28.3.195

Rao RAK, Khatoon A, Ashfaq A (2016) Application of Terminalia arjuna as potential adsorbent for the removal of $\mathrm{Pb}$ (II) from aqueous solution: thermodynamics, kinetics and process design. Desalination and Water Treatment 57:17808-17825. https://doi. org/10.1080/19443994.2015.1087878

Sahoo C, Gupta AK, Pal A (2005) Photocatalytic degradation of Methyl Red dye in aqueous solutions under UV irradiation using $\mathrm{Ag}+$ doped TiO2. Desalination 181:91-100. https://doi. org/10.1016/j.desal.2005.02.014

Sharifnia S, Khadivi MA, Shojaeimehr T, Shavisi Y (2016) Characterization, isotherm and kinetic studies for ammonium ion adsorption by light expanded clay aggregate (LECA). J Saudi Chem Soc 20:S342-S351. https://doi.org/10.1016/j.jscs.2012.12.003 
Sivalingam S, Sen S (2019) Efficient removal of textile dye using nanosized fly ash derived zeolite-x: kinetics and process optimization study. J Taiwan Inst Chem Eng 96:305-314. https://doi. org/10.1016/j.jtice.2018.10.032

Sobana N, Muruganadham M, Swaminathan M (2006) Nano-Ag particles doped $\mathrm{TiO}_{2}$ for efficient photodegradation of Direct azo dyes. J Mol Catal A Chem 258:124-132. https://doi.org/10.1016/j. molcata.2006.05.013

Song S, Xu L, He Z et al (2008) Photocatalytic degradation of C.I. Direct Red 23 in aqueous solutions under UV irradiation using $\mathrm{SrTiO}_{3} / \mathrm{CeO}_{2}$ composite as the catalyst. J Hazard Mater 152:13011308. https://doi.org/10.1016/j.jhazmat.2007.08.004

Taylor P, Soltani RDC, Khataee AR et al (2014) Desalination and Water Treatment Response surface methodological evaluation of the adsorption of textile dye onto biosilica/alginate nanobiocomposite : thermodynamic, kinetic, and isotherm studies. Science. https://doi.org/10.1080/19443994.2014.950344

Tünay O, Kabdasli I, Eremektar G, Orhon D (1996) Color removal from textile wastewaters. Water Sci Technol 34:9-16. https://doi. org/10.1016/S0273-1223(96)00815-3

Unnithan MR, Anirudhan TS (2001) The kinetics and thermodynamics of sorption of chromium(VI) onto the iron(III) complex of a carboxylated polyacrylamide-grafted sawdust. Ind Eng Chem Res 40:2693-2701. https://doi.org/10.1021/ie0009740

Unnithan MR, Vinod VP, Anirudhan TS (2004) Synthesis, characterization, and application as a chromium(VI) adsorbent of aminemodified polyacrylamide-grafted coconut coir pith. Ind Eng Chem Res 43:2247-2255. https://doi.org/10.1021/ie0302084

Vanni G, Escudero LB, Dotto GL (2017) Powdered grape seeds (PGS) as an alternative biosorbent to remove pharmaceutical dyes from aqueous solutions. Water Sci Technol 76:1177-1187. https://doi. org/10.2166/wst.2017.307

Wang R, Li Q, Xie D et al (2013) Synthesis of NiO using pine as template and adsorption performance for $\mathrm{Pb}$ (II) from aqueous solution. Appl Surf Sci 279:129-136. https://doi.org/10.1016/j. apsusc.2013.04.049

Wang J, Ying X, Liu J et al (2015) Controlled mechanical and swelling properties of urethane acrylate grafted calcium alginate hydrogels. Int J Biol Macromol 81:11-16. https://doi.org/10.1016/j.ijbio mac.2015.07.021

Zhang S, Xu F, Wang Y et al (2013) Silica modified calcium alginatexanthan gum hybrid bead composites for the removal and recovery of $\mathrm{Pb}$ (II) from aqueous solution. Chem Eng J 234:33-42. https:// doi.org/10.1016/j.cej.2013.08.102

Zhang Q, Zhang T, He T, Chen L (2014) Removal of crystal violet by clay/PNIPAm nanocomposite hydrogels with various clay contents. Appl Clay Sci 90:1-5. https://doi.org/10.1016/j. clay.2014.01.003

Zhang F, Ma B, Jiang X, Ji Y (2016) Dual function magnetic hydroxyapatite nanopowder for removal of malachite green and Congo red from aqueous solution. Powder Technol 302:207-214. https://doi.org/10.1016/j.powtec.2016.08.044

Publisher's Note Springer Nature remains neutral with regard to jurisdictional claims in published maps and institutional affiliations. 